\title{
Extra Oxygen Leads to Bubble Trouble: Portal Vein Gas Embolism from 3\% Hydrogen Peroxide Ingestion
}

Joowhan Sung ${ }^{1}$, Francesca Cossarini ${ }^{1}$, Leonidas Palaiodimos ${ }^{2}$, Benjamin Benson ${ }^{3}$, Mimoza Meholli ${ }^{1}$

1. Department of Medicine, Albert Einstein College of Medicine/ Jacobi Medical Center 2. Internal Medicine, Montefiore Medical Center / Albert Einstein College of Medicine, New York, USA 3. Department of Radiology, Albert Einstein College of Medicine/ Jacobi Medical Center

$\square$ Corresponding author: Joowhan Sung, joowhan.sung@gmail.com

Disclosures can be found in Additional Information at the end of the article

\section{Abstract}

Hydrogen peroxide ingestion can cause gastric irritation and gas embolism; however, most reported cases are from the highly concentrated ( $\geqslant 35 \%)$ solution used in the industry and data on household-used 3\% solution ingestion is scarce. We report a case of a portal vein gas embolism after ingestion of $3 \%$ hydrogen peroxide. The patient was managed conservatively with antacids and improved in 48 hours. Endoscopy and hyperbaric treatment were considered but not pursued. This is the fifth reported case of gas embolism after $3 \%$ hydrogen peroxide ingestion and stands in line with other reports where the patients improved with conservative management.

Categories: Emergency Medicine, Internal Medicine, Gastroenterology

Keywords: hydrogen peroxide poisoning, portal vein gas embolism, low concentration hydrogen peroxide

\section{Introduction}

Hydrogen peroxide is an oxidizing agent used as a disinfectant in the household, for wound irrigation and instrument sterilization in medicine, and as a bleaching agent in manufacture. Accidental exposure to hydrogen peroxide is usually benign, however, ingestion of large quantities or high concentration can cause damage to the gastrointestinal tract and oxygen generated from catabolism could cause gas embolism, including portal vein and cerebral embolism [1-2]. Gas embolism has been reported in patients with concentrated ( $\geqslant 35 \%)$ hydrogen peroxide ingestion, however, cases caused by $3 \%$ concentration are rare [2-3]. We present a case of portal vein gas embolism caused by the accidental ingestion of hydrogen peroxide $3 \%$ solution.

\section{Case Presentation}

On a hot summer day in New York City, a 46-year-old male with a history of diabetes presented to the emergency department with sudden onset epigastric pain, nausea, and repetitive vomiting. His symptoms started soon after the accidental ingestion of $350 \mathrm{cc}$ of $3 \%$ hydrogen peroxide solution, which was mistakenly taken as water by the patient. The patient presented to the emergency room approximately 14 hours after the ingestion. By that time, he had already vomited 10 times, including three episodes of dark bloody vomitus. 


\section{Cureus}

On examination, he was afebrile and his abdomen was soft but with mild tenderness in the right upper and left upper quadrants. Laboratory investigations, including liver function tests, were unremarkable except for a mildly elevated total bilirubin of $1.4 \mathrm{mg} / \mathrm{dL}$. A computed tomography (CT) scan of the abdomen and pelvis was performed, which revealed gastric wall thickening and diffusely scattered gas in the hepatic portal system (Figure 1). The patient was treated conservatively with intravenous hydration and antacids and was placed in the Trendelenburg position. Hyperbaric treatment was considered; however, it was not pursued as the patient's symptoms were improving. Endoscopy was not pursued. Our patient's symptoms improved over the following 48 hours and the patient was subsequently discharged.

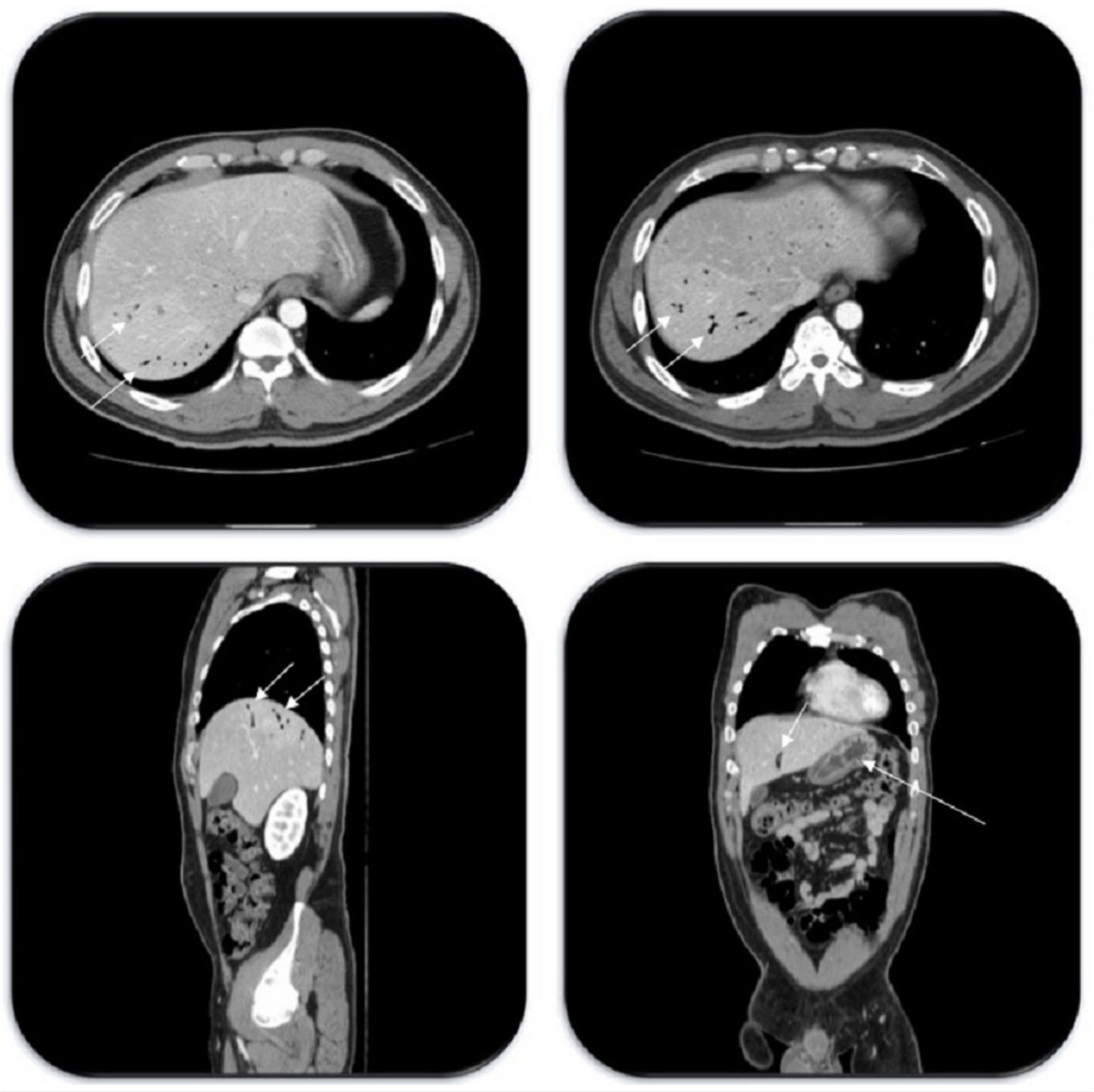

FIGURE 1: Axial (upper two images), sagittal (left lower image), and coronal (right lower image) abdominal CT scan images showing diffuse portal venous gas (short arrows) and gastric wall thickening (long arrow) up to $1 \mathrm{~cm}$

CT: computed tomography

\section{Discussion}

Hydrogen peroxide is used at a wide range of concentrations (3\% to 90\%) [4]. Low concentration (3\%) is used in the household and high concentration (35\%) is used in the 
industry. It is caustic for human tissues and can cause damage if inhaled, ingested, or on contact with the skin. Inhalation can cause a spectrum of damage, from mild coughing to severe pulmonary edema, while skin contact leads to inflammation, blistering, and skin damage. Ingestion leads to irritation and inflammation of the gastrointestinal tract, resulting in nausea, vomiting, and sometimes hematemesis from hemorrhagic gastritis. Gas embolism, the most serious consequences, has mostly been reported after the ingestion of high concentration (35\%) hydrogen peroxide [2]. Low concentration (3\%) hydrogen peroxide ingestion is usually considered to be benign [3]. Our literature search revealed that only four other cases of portal vein embolism after the ingestion of $3 \%$ hydrogen peroxide have been described, making this case the fifth [5-8].

The mechanisms through which hydrogen peroxide causes tissue damage are corrosion, lipid peroxidation, and oxygen formation. Cells are protected from the oxidative damage of hydrogen peroxide by catalase, an enzyme present in the peroxisomes of nearly all aerobic cells, which catalyzes the decomposition of hydrogen peroxide to oxygen and water $\left(2 \mathrm{H}_{2} \mathrm{O}_{2} \rightarrow 2 \mathrm{H}_{2} \mathrm{O}+\mathrm{O}_{2}\right)$

[9]. However, the formation of large amounts of oxygen can have serious consequences. If a large volume of oxygen accumulates in a hollow cavity, such as the stomach, this can lead to distention, resulting in significant abdominal pain and possible rupture. In addition, oxygen is freely exchanged with the capillaries and if the amount of oxygen produced exceeds its maximum solubility, gas embolization may occur. Portal vein and systemic embolic events, including brain infarction due to gas embolism following hydrogen peroxide ingestion have been reported $[1,9]$.

Since hydrogen peroxide is colorless and odorless, it can be easily mistaken for water, and it is important to maintain awareness of its toxicity even at low concentrations (3\%). Our patient ingested a relatively large amount (350 cc) of $3 \%$ hydrogen peroxide, thus explaining the significant symptoms experienced and the formation of large amounts of oxygen leading to gas embolism into the portal vein system. When $1 \mathrm{~mL}$ of $3 \%$ hydrogen peroxide is catalyzed, it produces $10 \mathrm{~mL}$ of oxygen gas under normal temperature and pressure. While ingestion is the most common cause of gas embolism by hydrogen peroxide, cases have been reported where gas embolism was observed after skin contact with hydrogen peroxide in a surgical patient [10].

There are no standardized guidelines for the diagnosis and treatment of hydrogen peroxide ingestion and gas embolism. History is essential to identify the type of exposure and symptoms, and signs and symptoms such as abdominal pain, nausea, vomiting, and foaming at the mouth are suggestive of hydrogen peroxide ingestion. There is no consensus on the most appropriate diagnostic workup, however, endoscopy can be useful to evaluate for gastritis [6]. Although the plain film can identify portal venous gas embolism, the CT scan is the most frequently used imaging method [2]. In addition, no consensus exists regarding treatment. Most cases are managed conservatively. Gastrointestinal symptoms and mucosal irritation can be treated with $\mathrm{H}_{2}$ blockers or proton pump inhibitors, while in severe cases, where there is suspicion for airway compromise, endotracheal intubation may be warranted. Portal vein gas embolism is generally treated conservatively, however, hyperbaric oxygen has shown positive results in patients who ingested a concentrated solution [1-2]. Exposing patients to higher oxygen pressure facilitates the dissolution of gas into the blood system and the excess gas can be expelled via respiration. Our patient did not undergo such treatment and significantly improved in the following 48 hours. This is consistent with other previously reported 3\% ingestion cases where patients are managed conservatively with positive outcomes (Table 1). 


\section{Cureus}

\begin{tabular}{|c|c|c|c|c|c|c|}
\hline Author & Age & Sex & Presenting symptoms & $\begin{array}{l}\text { Ingested } \\
\text { amount }\end{array}$ & Treatment & Clinical course \\
\hline $\begin{array}{l}\text { Arnsfield } \\
\text { et al. [5] }\end{array}$ & 21 & M & Vomiting, Epigastric pain & $\begin{array}{l}\text { One } \\
\text { mouthful }\end{array}$ & $\begin{array}{l}\text { Intubation for airway } \\
\text { protection, Proton pump } \\
\text { inhibitor, Antibiotics }\end{array}$ & $\begin{array}{l}\text { Improved, Resolution of } \\
\text { portal gas in repeat imaging } \\
\text { in three days }\end{array}$ \\
\hline $\begin{array}{l}\text { Moon et } \\
\text { al. [6] }\end{array}$ & 25 & $\mathrm{~F}$ & Vomiting, Epigastric pain & $40 \mathrm{cc}$ & Oxygen, H2 blocker & $\begin{array}{l}\text { Improved, Resolution of } \\
\text { portal gas in repeat imaging } \\
\text { in two days }\end{array}$ \\
\hline $\begin{array}{l}\text { Rackoff } \\
\text { et al. [7] }\end{array}$ & 2 & M & $\begin{array}{l}\text { Vomiting, Foaming } \\
\text { around the mouth }\end{array}$ & Unknown & Oral antacids & Improved \\
\hline $\begin{array}{l}\text { Tanaka } \\
\text { et al. [8] }\end{array}$ & 73 & M & $\begin{array}{l}\text { Hematemesis, Epigastric } \\
\text { pain }\end{array}$ & Unknown & Proton pump inhibitor & Improved \\
\hline
\end{tabular}

TABLE 1: Previously reported cases of portal vein gas embolism after ingestion of $3 \%$ hydrogen peroxide solution

\section{Conclusions}

To the best of our knowledge, this is the fifth case of gas embolism after $3 \%$ hydrogen peroxide ingestion, suggesting that a $3 \%$ solution can also lead to air embolism, and prompt treatment and monitoring is necessary. Furthermore, our patient's clinical improvement with conservative management is in line with most of the previous reports and can reassure clinicians working in areas where hyperbaric treatment options are not available.

\section{Additional Information}

\section{Disclosures}

Human subjects: Consent was obtained by all participants in this study. Conflicts of interest: In compliance with the ICMJE uniform disclosure form, all authors declare the following: Payment/services info: All authors have declared that no financial support was received from any organization for the submitted work. Financial relationships: All authors have declared that they have no financial relationships at present or within the previous three years with any organizations that might have an interest in the submitted work. Other relationships: All authors have declared that there are no other relationships or activities that could appear to have influenced the submitted work.

\section{References}

1. Rider SP, Jackson SB, Rusyniak DE: Cerebral air gas embolism from concentrated hydrogen peroxide ingestion. Clin Toxicol. 2008, 46:815-818. 10.1080/15563650701725136

2. French LK, Horowitz BZ, McKeown NJ: Hydrogen peroxide ingestion associated with portal venous gas and treatment with hyperbaric oxygen: a case series and review of the literature. Clin Toxicol. 2010, 48:533-538. 10.3109/15563650.2010.492526

3. Henry MC, Wheeler J, Mofenson HC, Caraccio TR, Marsh M, Comer GM, Singer UJ: Hydrogen peroxide 3\% exposures. Clin Toxicol. 1996, 34:323-327. 10.3109/15563659609013797

4. Watt BE, Proudfoot AT, Vale JA: Hydrogen peroxide poisoning. Toxicol Rev. 2004, 23:51-57. 


\section{Cureus}

10.2165/00139709-200423010-00006

5. Arnfield E, Bhardwaj H, Brown N, Handy M, Cleland P: Hydrogen peroxide poisoning: an unusual cause of portal venous gas. BJR. 2015, 2:20150283. 10.1259/bjrcr.20150283

6. Moon JM, Chun BJ, Min YI: Hemorrhagic gastritis and gas emboli after ingesting $3 \%$ hydrogen peroxide. J Emerg Med. 2006, 30:403-406. 10.1016/j.jemermed.2005.05.036

7. Rackoff WR, Merton DF: Gas embolism after ingestion of hydrogen peroxide . Pediatrics. 1990, 85:593-594.

8. Tanaka Y, Yoshioka T, Kusaka T: Hydrogen peroxide ingestion: a rare case of portal venous gas. Gastrointest Endosc. 2014, 79:835-837. 10.1016/j.gie.2013.11.039

9. Burns RA, Schmidt SM: Portal venous gas emboli after accidental ingestion of concentrated hydrogen peroxide. J Emerg Med. 2013, 45:345-347. 10.1016/j.jemermed.2013.02.001

10. Vidil L, Racioppi L, Biais M, Revel P, Sztark F: Iatrogenic gas embolism after the use of hydrogen peroxide [Article in French]. Ann Fr Anesth Reanim. 2008, 27:735-737.

10.1016/j.annfar.2008.06.008 